\title{
Role of Delamination and Crystallography on Anisotropy of Charpy toughness in API-X80 steel
}

\author{
M. S. Joo a, D.-W. Suh ${ }^{\text {, }}$,J. H. Bae ${ }^{\mathrm{c}}$, H. K. D. H. Bhadeshiaa,b \\ ${ }^{a}$ Graduate Institute of Ferrous Technology, POSTECH, Pohang, Republic of Korea \\ ${ }^{b}$ Materials Science and Metallurgy, University of Cambridge, Cambridge, U.K. \\ ${ }^{c}$ Technical Research Laboratories, POSCO, Pohang, Republic of Korea
}

\begin{abstract}
The orientation dependence of Charpy toughness has been investigated in API-X80 linepipe steel. The occurrence of delamination and preferential alignment of $\{100\}$ cleavage planes are found to contribute to the observed anisotropy in Charpy properties. Delamination is also related to the presence of banding in the hot-rolled alloy, and the additional plasticity it entails during the process of fracture leads to an effective increase in toughness. As a consequence, the toughness is worst when the Charpy specimen is machined at $45^{\circ}$ to the rolling direction because the extent of delamination at that orientation is minimal. The rolling and transformation textures also lead to a greater propensity of $\{100\}$ ferrite planes parallel to the fracture surface for the $45^{\circ}$ orientation, leading to a further decrease in toughness. Some revealing results are also reported for unconventional Charpy test orientations in which the notch is prepared parallel to the plate.
\end{abstract}

Keywords: linepipe, X80 steel, anisotropic properties, delamination, crystallographic texture

Email address: athpimo@postech.ac.kr, +8211 366 0017, corresponding author (M. S. Joo) 


\section{Introduction}

Pipes can be manufactured by welding spirals of hot-rolled steel; this process has a cost advantage relative to one in which the steel is seam welded after bending into a tube shape. Even though properties such as the Charpy toughness and strength meet minimum specifications, the existence of anisotropy can compromise, for example, the stability of the pipe to buckling [1]. In the case of spiral pipes, the least tough Charpy orientation also happens to coincide with the circumferential direction which experiences the largest (hoop) stress [2].

It is known that orientation-dependent properties in linepipe steels are related to inclusions, microstructural anisotropy and unfavourable crystallographic texture. In the context of inclusions, manganese sulphides and silicates become elongated during the rolling process and hence contribute to mechanical anisotropy. Bands of pearlite resulting from solidificationinduced chemical segregation obviously lead to directional properties, but mostly in the ductile fracture regime rather than in the temperature range corresponding to the ductile-tobrittle transition [3-12]. An elongated grain structure, for example that generated by warmrolling with a low finish-rolling temperature, has been shown to cause variations in the tensile strength and impact properties according to direction relative to the elongated structure [13]. The role of crystallographic texture on the Charpy anisotropy is usually explained in terms of the exaggerated alignment of cleavage planes along particular orientations, but such interpretations could benefit from a greater degree of scrutiny [14-16]. Indeed, some early results on planar anisotropy in a different context suggest that the effect of texture is small and largely on ductile fracture [17], especially when the grain structure itself is directional [13]. In contrast, work on modern X80 linepipe tends to show no clear correlation between the $\{100\}$ planes and ductile fracture parallel to the rolling plane [18].

The purpose of the present work was to clarify the origin of anisotropy in Charpy energy in API-X80 linepipe steel, as a function of test temperature, but focusing on the range where the fracture mode changes from ductile to brittle failure. The impact properties between 
$-100^{\circ} \mathrm{C}$ and $20^{\circ} \mathrm{C}$ are quantified for rolling, transverse and diagonal directions and combined with a fracture surface analysis. Some special orientations of Charpy samples are additionally studied in order to reveal detailed information on the role of delamination.

\section{Experimental Method}

The chemical composition and processing conditions of the steel are listed in Table 1. The slab was subjected to austenitisation $\left(T>1100^{\circ} \mathrm{C}\right)$ and hot-rolled above the $A r_{3}$, the temperature at which austenite begins to transform into ferrite during cooling. The final thickness of the steel was $18 \mathrm{~mm}$. Note that all samples were $10 \mathrm{~mm}$ thickness, with $4 \mathrm{~mm}$ removed from each surface by machining, and hence represent the central layer of the plate.

Microstructural studies were carried out using optical, scanning electron and transmission electron microscopy. The samples for the former two methods were prepared by polishing and etching using $2 \%$ nital. Thin foil samples for transmission electron microscopy were made from $80-90 \mu \mathrm{m}$ thick and $3 \mathrm{~mm}$ diameter discs, which were electropolished in $5 \%$ perchloric acid with $95 \%$ acetic acid at $15^{\circ} \mathrm{C}$. Samples for electron back-scattered diffraction (EBSD) and crystallographic determinations were mechanically polished with colloidal silica in the final polishing stage. Orientation images were taken at an operating voltage of $20 \mathrm{kV}$, a working distance of $20 \mathrm{~mm}$ and a tilt angle of $70^{\circ}$. The size of the scanned regions was $100 \times 100 \mu \mathrm{m}^{2}$. Data were collected using a step size of $0.2 \mu \mathrm{m}$ at a magnification of $\times 2000$. Tensile specimens were machined according to the ASTM E8 standard as shown in Fig. 1a. Tensile tests were conducted at room temperature, using a crosshead speed of $3.6 \mathrm{~mm} \mathrm{~min}{ }^{-1}$ with full-sized test coupons with a gauge length of $50 \mathrm{~mm}$. The orientations of the tensile test specimens are shown in the Fig. 1b, with ' $\mathrm{L}$ ', 'T' and ' $\mathrm{D}$ ' standing for longitudinal (parallel to the rolling direction), transverse and diagonal orientations respectively.

Full-sized V-notched Charpy specimens of dimensions $10 \times 10 \times 55 \mathrm{~mm}$, each with a $2 \mathrm{~mm}$ deep $\mathrm{V}-$ notch, were used in tests conducted between ambient temperature to $-100^{\circ} \mathrm{C}$. The test 
temperature was controlled using a K-type thermocouple attached to the specimen. Fig. 1c shows the conventionally specified orientations of the Charpy specimen relative to the steel processing directions; in the designations L-T, T-L and D-D, the first letter represents the sample direction and the second the impact direction. The notches in this case are normal to the plane of the plate. Fig. 1d shows additional tests done but with the notches parallel to the plate, with L-S, T-S and D-S orientations. Here, S stands for short-transverse direction parallel to the plate normal. Note that the planes on which fracture occurs are the same for the conventional and additional orientations in Fig. 1, but the difference originates from the direction of impact during the Charpy test.

\section{Results and Discussion}

\section{Microstructure}

Figures 2a,b show the micrographs of the steel in its hot-rolled state. There is a mixed microstructure of coarse allotriomorphic ferrite together with some finer transformation products, i.e., pearlite and the so-called MA constituent [19] which is a mixture of martensite and retained austenite. Allotriomorphic ferrite $[20,21]$ is sometimes referred to as 'proeutectoid ferrite' but the latter is a more general term which can include, for example, Widmanstätten ferrite. Its diffusional mechanism of formation leaves it with a relatively small dislocation density and as a consequence, each grain of such ferrite is free from large distortions and has a uniform crystallographic orientation. Its presence and distribution can therefore be revealed as the black grains in the grain orientation map shown in Fig. 2e, where boundaries are identified by black lines across which the misorientation is greater than $15^{\circ}$, and there is an orientation spread less than $1.5^{\circ}$ within each black grain. Therefore, the black regions are regarded as allotriomorphic ferrite whereas the white regions have large orientation gradients because they correspond to a predominantly bainitic microstructure as will be discussed later. 
There is also evidence of microstructural banding of the type associated with chemical segregation, particularly manganese, inherited from the solidification stage and spread into layers by the rolling deformation. Manganese is known to play a prominent role in the development of bands because transformation to allotriomorphic ferrite occurs first in Mn-depleted regions so that the residual austenite becomes enriched in carbon, to transform subsequently into pearlite or harder phases such as bainite depending on the rate of cooling experienced by the steel. The hardness (HV) values in the fine microstructure and the region containing allotriomorphic ferrite are found to be approximately $266 \pm 2$ and $230 \pm 3$, respectively.

Some of the structure is too fine to resolve using optical or conventional scanning electron microscopy, but transmission electron microscopy suggests that it is some form of plate-like, heavily dislocated structure, probably bainite given that the steels are cooled continuously, Fig. 3a. Notice that structures like these are often referred to as 'acicular ferrite' in the terminology of linepipe steels, but they do not resemble the acicular ferrite that is found in steel weld metals, where plates nucleate intragranularly on non-metallic inclusions to form a chaotic microstructure which is good for toughness [22-24]. Instead, the microstructure in Fig. $3 \mathrm{a}$ is a consequence of continuous cooling transformation in which the final morphology is influenced not only by the shape of individual plates during growth, but also impingement between independently nucleated plates as the austenite is exhausted. It is for this reason that some grains appear more equiaxed than plate-like. There is also evidence of some cementite precipitation, as shown by the arrow in Fig. 3b, but the quantity involved is very small due to the low carbon concentration of the steel.

\section{Mechanical properties and fracture surfaces}

The tensile properties measured as a function of orientation are summarised in Table 2, representing three tensile tests at each orientation. The transverse orientation is the strongest although a somewhat greater ductility is associated with the diagonal test-orientation, but the differences in ductility are small and within the scatter observed at each orientation. 
Fig. 4 shows the Charpy test data for what is designated here as the conventional notch orientation where the notch is parallel to the plate-normal, in order to distinguish these results from the additional tests that are reported later in the text, where the notch lay in the plane of the steel plate (Fig. 1d). As might be expected, and consistent with the tensile test data, anisotropy is minimal when failure is in the ductile regime, or when the sample fails in a completely brittle manner during tests at $-100^{\circ} \mathrm{C}$. In contrast, the orientation dependence of Charpy energy is marked in the ductile-brittle transition temperature range, with the D-D orientation faring worst; this might be expected given that Fig. 4a shows that the impact transition temperature itself is orientation-dependent. Note that it is unlikely that the small differences in strength noted in the data of Table 2 can be responsible for the observed anisotropy of Charpy properties [25]. Fig. 4c-e shows that the change in fracture mode as the test temperature is reduced, from fully ductile to brittle failure, is gradual, consistent with the gentle slopes of the Charpy impact energy curves as a function of temperature.

A striking feature of many of the fracture surfaces of the impact specimens is the splitting apart of the steel on planes normal to that of overall fracture, as highlighted by the white arrows on Fig. 5. This phenomenon is often referred to as delamination and is seen to occur parallel to the rolling plane for specimens with $\mathrm{L}-\mathrm{T}$ and $\mathrm{T}-\mathrm{L}$ orientations for $-20^{\circ} \mathrm{C}$ to $-60^{\circ} \mathrm{C}$ but with D-D orientation only for $-20^{\circ} \mathrm{C}$ (white arrows). This weakness parallel to the rolling plane is a consequence of inclusion alignment or microstructural anisotropy.

Delamination in the ductile regime is reported to reduce the upper shelf energy because it is related with separation on $\{100\}_{\alpha}$ cleavage planes [26]. It can contribute to the toughness in the transition region when the split occurs on a plane not containing the notch. From the variation in Charpy energy and the corresponding fracture surfaces shown in Figs 4 and 5 , it is evident that the $\mathrm{L}-\mathrm{T}$ and $\mathrm{T}-\mathrm{L}$ orientations with higher impact energy in the ductile-brittle transition region always have the delamination as a part of the fracture energy absorption process. For the D-D orientation, the impact energy is comparable to those of 
other orientations at $-20^{\circ} \mathrm{C}$ where the delamination is a feature of all fracture surfaces, but the energy decreases sharply at lower temperatures in the absence of splitting. This clearly indicates a relationship between the observed Charpy-energy anisotropy and the occurrence of delamination at fracture surface.

\section{Role of Crystallography}

It is possible that a propensity of grains which have $\{100\}$ planes parallel to that of fracture during Charpy testing can lead to brittle behaviour. Fig. 6 shows the estimated fraction of ferrite grains as determined using EBSD and assuming that a grain is defined by a misorientation of $11.25^{\circ}$ relative to its neighbour. The plot is therefore as a function of the angles $0^{\circ}, 22.5^{\circ}, 45^{\circ}, 67.5^{\circ}$ and $90^{\circ}$ between the $\{100\}$ plane normal and the rolling direction (RD). The choice of the angle $11.25^{\circ}$ is because it is half the tilt angle $22.5^{\circ}$, so that overlap of information is avoided between the scans. Notice that the bar chart is symmetrical about the $45^{\circ}$ angle relative to the rolling direction because of the symmetry of the $\{100\}$ planes which are mutually inclined at $90^{\circ} \mathrm{C}$. Therefore, the fractions at $0^{\circ}, 90^{\circ}$ to $\mathrm{RD}$ and at $22.5^{\circ}$, $67.5^{\circ}$ to $\mathrm{RD}$ came from the same grains.

The experimental data are compared against what is expected if the distribution of grain orientations is random; the computer simulation considered a set of 10,000 grains, with care being taken to ensure that the set of generated grains satisfied the distribution of misorientation angles for a randomly textured polycrystalline material [27]. It is obvious that the steel has pronounced crystallographic texture relative to a random distribution, Fig. 6, and that the there is an exaggerated fraction of grains having $\{100\}$ plane-normals at $45^{\circ}$ to the rolling direction. This in turn implies that the crystallographic texture in the hot-rolled steel makes it vulnerable to brittle fracture in the D-D orientation because there is a preponderance of $\{100\}$ planes which are parallel to the fracture surface. Such an interaction between texture and properties would be most pronounced at low temperatures where cleavage occurs, as is observed experimentally. 


\section{Further Aspects of Delamination}

It is well known in fracture mechanics that the constraint to plastic deformation is maximised in thick samples under plane strain conditions, so that the energy absorbed during fracture is reduced when compared with a thin sample subjected to plane stress conditions [28]. It is for this reason that a notched tensile specimen behaves in a brittle manner when pulled in tension, relative to one with the same cross-sectional area but without a notch. This is also the reason why shear lips occur on the edges of broken Charpy samples, since the constraints are relaxed in the proximity of the free surfaces [29]. It has been pointed out previously in a study of thickness effects [30] that the occurrence of delamination reduces the out-of-plane constraint; this would in turn lead to an increase in the tendency for ductile fracture and hence a higher impact energy in a Charpy test. So-called delamination toughening has long been known to lead to improved toughness in a wide variety of materials, for example in ceramics [31], carbon [32], and fine-grained steels [33-36]. In particular, delaminations that form parallel to the plate surface can lead to a reduction in the impact transition temperature [37] although excessive fissuring can compromise the upper shelf energy of Charpy tests [38]. It is interesting that the delamination itself is created by brittle fracture, as illustrated in Fig. 7, but nevertheless leads to an increase in Charpy toughness as long as it precedes gross fracture. We have verified using fractography on many samples that the majority of the fracture leading to delamination occurs in a brittle manner.

The occurrence of delamination might be attributed to crystallographic texture; cleavage delaminations are known to occur in warm-rolled steel and have been discussed in terms of texture [39]. Other causes include intergranular failure along prior austenite boundaries, segregation of $\mathrm{P}$ and $\mathrm{S}$, anisotropy of microstructures, banding and aligned particles and inclusions [40-42]. Some of these factors can clearly contribute in the present context, but Fig. 8 indicates that microstructural banding is an important culprit. A close examination

of the (arrowed) regions on either side of the separation in Fig. 8b shows that the delam- 
ination occurs between the relatively clean and coarse ferrite, and on the opposite side, a refined region richer in the harder phases. This might be expected given the mechanical incompatibilities that must inevitable exist between the bands.

However, there also seems to be a significant difference in the crystallography of the fully brittle regions on either side of the delamination, as shown by the orientation maps in Fig. 8c; in other words, the microscopic texture is different in the coarser and refined bands, and this in turn must add to the mechanical incompatibilities. Similar strong differences are seen in the grain orientation spread maps which relate to variations in orientation within allegedly uniform grains.

\section{Additional Charpy Notch Orientations}

To further establish the role of delamination, Charpy tests were conducted with the notches parallel to the rolling plane in the hope that this would promote delamination since the maximum principal (tensile) stress then should be normal to the rolling plane. Fig. 9 shows clearly that all such specimens tested at $-20^{\circ} \mathrm{C}$ and $-40^{\circ} \mathrm{C}$ show a large, single split. For the samples tested at $20^{\circ} \mathrm{C}$, the delaminations occur in a deep and narrow manner, and they become wider when tested at $-40^{\circ} \mathrm{C}$. Consistent with these observations, Fig. 10 shows that the extent of anisotropy in the transition temperature range is significantly reduced, thus confirming the seminal contribution of delamination to the anisotropy of properties.

\section{Summary}

There are many causes to be found in the literature for the anisotropy of fracture toughness in linepipe steels. A set of experiments has been performed to establish the cause of orientation dependence in a specific variant of X80 steel.

1. It has been established experimentally that Charpy specimens with notches along the plate normals, exhibit relatively low impact properties in the transition temperature 
region, when machined from an orientation which makes an angle of $45^{\circ}$ to the rolling direction.

2. These results cannot be understood in terms of relatively minor variations in tensile strength and ductility as a function of orientation within the hot-rolled steel plate.

3. By conducting Charpy tests in conventional orientations as specified in standards, and comparing against additional notch orientations parallel to the plane of the plate, it has been possible to demonstrate that delamination plays a large role in causing the anisotropy of impact toughness. The cause of the delamination is attributed to the presence of microstructural banding, with variations in crystallography between adjacent bands.

4. A secondary contribution to anisotropy comes from crystallographic texture which in some orientations places a large density of cleavage planes parallel to the fracture plane of the Charpy specimen.

Acknowledgments: The authors are grateful for support from the POSCO Steel Innovation Programme, and to the World Class University Programme of the National Research Foundation of Korea, Ministry of Education, Science and Technology, project number R32-2008-000-10147-0. 


\section{References}

[1] E. Torselletti, L. Vitali, R. Bruschi, in: Proceedings of Super-High Strength Steels, Associazione Italian di Metallurgica, Rome, Italy, 2005, pp. 1-18.

[2] K. Kim, J.-H. Bae, in: 2008 7th International Pipeline Conference, volume 3, ASME, New York, USA, 2008, pp. 167-173.

[3] C. E. Sims, Trans. Met. Soc. AIME 215 (1959) 367-393.

[4] T. J. Baker, J. A. Cameron, Journal of the Iron and Steel Institute 210 (1972) 680-690.

[5] J. M. Hodge, R. H. Frazier, G. W. Boulger, Trans. Metall. Soc. AIME 215 (1959) 745753.

[6] G. S. Kramer, G. M. Wilkowski, W. A. Maxey, Flaw tolerance of spiral-welded line pipe, Technical Report L51514, American Gas Association, Washington, D. C., USA, 1987.

[7] V. A. Burnos, T. P. Vaschilo, L. E. Balandina, Industrial Laboratory (USSR) 54 (1988) $548-550$.

[8] G. M. Wilkowski, J. Ahmad, F. Brust, N. Ghadiali, P. Krishnaswamy, M. Landow, C. W. Marschall, P. Scott, P. Vieth, Short cracks in piping and piping welds, Technical Report NUREG/CR-4599-Vol.1-No.1; BMI-2173-Vol.1-No.1, Nuclear Regulatory Commission, Ohio, USA, 1991.

[9] P. Krishnaswamy, P. Scott, R. Mohan, S. Rahman, Y. H. Choi, F. Brust, T. Kilnski, N. Ghadiali, C. Marchall, G. Wilkowski, Fracture behavior of short circumferentially surface-cracked pipe, Technical Report NUREG/CR-6298, Nuclear Regulatory Commission, Ohio, U. S. A., 1995.

[10] Y. I. Matrosov, I. E. Polyakov, Stal 2 (1976) 162-167. 
[11] P. C. Wilson, Y. V. Murty, T. Z. Kattamis, R. Mehrabian, Metals Technology 2 (1975) $241-244$.

[12] S. J. Garwood, in: Application of Fracture Mechanics to Materials and Structures, Martinus Nijhoff Publishers, Leiden, Holland, 1984, pp. 939-950.

[13] B. Mintz, W. B. Morrison, P. I. Welch, G. J. Davies, in: G. Gottstein, K. Lucke (Eds.), Texture of Materials, volume 2, Springer-Verlag, Berlin, Germany, 1978, pp. 465-474.

[14] G. J. Baczynski, J. J. Jonas, L. E. Collins, Metallurgical \& Materials Transactions A 30 (1999) 3045-3054.

[15] R. Petrov, O. L. Garcia, N. S. Mourino, L. Kestens, J. H. Bae, K. B. Kang, Materials Science Forum 558-559 (2007) 1429-1434.

[16] R. H. Petrov, O. L. Garcia, J. J. L. Mulders, A. C. C. Reis, J. H. Bae, L. A. I. Kestens, Y. Houbaert, Materials Science Forum 550 (2007) 625-630.

[17] B. Mintz, W. B. Morrison, P. P. Morris, G. J. Davies, in: G. J. Davies (Ed.), Texture and Properties of Materials, The Metals Society, London, U.K., 1976, pp. 224-234.

[18] I. Pyshmintsev, A. Gervasyev, R. H. Petrov, V. C. Olalla, L. A. I. Kestens, Materials Science Forum 702-703 (2012) 770-773.

[19] H. Ikawa, H. Oshige, T. Tanoue, Trans. Japan Welding Society 11 (1980) 3-12.

[20] C. A. Dubé, H. I. Aaronson, R. F. Mehl, Revue de Metallurgie 55 (1958) 201-210.

[21] H. K. D. H. Bhadeshia, Progress in Materials Science 29 (1985) 321-386.

[22] Y. Ito, M. Nakanishi, The Sumitomo Search 15 (1976) 42-62.

[23] D. J. Abson, R. J. Pargeter, International Materials Reviews 31 (1986) 141-194. 
[24] H. K. D. H. Bhadeshia, in: S. A. David, J. M. Vitek (Eds.), International Trends in Welding Research, ASM International, Ohio, U. S. A., 1992, pp. 213-222.

[25] J. A. Kapp, J. H. Underwood, Correlation between fracture toughness, Charpy V-notch impact energy, and yield strength for ASTM A723 steel, Technical Report ARCCBMR-92008, US Army Armament Research, Development and Engineering Centre, New York, USA, 1992.

[26] R. Schofield, G. Rowntree, N. V. Sarma, R. T. Weiner, Metals Technology 1 (1974) $325-331$.

[27] J. K. Mackenzie, Biometrika 45 (1958) 229-240.

[28] J. F. Knott, Fundamentals of Fracture Mechanics, Butterworths, London, pp. 234-241.

[29] R. Song, D. Pong, D. Raabe, Acta Materialia 53 (2005) 4881-4892.

[30] W. Guo, H. Dong, M. Lu, X. Zhao, International Journal of Pressure Vessels and Piping 79 (2002) 403-412.

[31] W. Clegg, K. Kendall, N. Alford, J. Birchall, T. Button, Nature 347 (1990) 455-457.

[32] M. Sakai, R. C. Bradt, F. D. B, Journal of Materials Science 21 (1986) 1491-1501.

[33] Y. Kimura, T. Inoue, E. Yin, K. Tsuzaki, Science 320 (2008) 1057-1060.

[34] Y. Kimura, T. Inoue, E. Yin, K. Tsuzaki, ISIJ International 50 (2010) 152-161.

[35] T. Inoue, F. Yin, Y. Kimura, K. Tsuzaki, S. Ochiai, Metallurgical \& Materials Transactions A 41 (2010) 341-355.

[36] B. Mintz, E. Maina, W. B. Morrison, Materials Science and Technology 23 (2007) 347354. 
[37] E. Maina, D. N. Crowther, J. R. Banerjee, B. Mintz, Materials Science and Technology 28 (2011) DOI 10.1179/1743284711Y.0000000061.

[38] B. Mintz, E. Maina, W. B. Morrison, Materials Science and Technology 24 (2008) 177188.

[39] D. L. Bourell, O. D. Sherby, Metallurgical transactions A 14 (1983) 2563-2566.

[40] I. Tamura, H. Sekine, T. Tanaka, C. Ouchi, Thermomechanical processing of highstrength low-alloy steels, Butterworth \& Co., London, U.K., 1988.

[41] A. J. McEvily, R. H. Bush, Trans. ASM 55 (1962) 654-666.

[42] S. Y. Shin, S. Y. Han, B. Hwang, C. G. Lee, S. Lee, Materials Science and Engineering: A 517 (2009) 212-218. 
Table 1: Chemical composition (wt\%) and thermomechanical processing conditions. $A r_{3}$ represents the temperature at which austenite begins to decompose during cooling. Please note that the exact chemical composition and processing is proprietary information.

\begin{tabular}{ccccccc}
\hline $\mathrm{C}$ & $\mathrm{Mn}$ & $\mathrm{Si}$ & $\mathrm{P}+\mathrm{S}$ & $\mathrm{Nb}+\mathrm{Ni}+\mathrm{Mo}$ & $\mathrm{Ti}+\mathrm{Al}$ & $\mathrm{N}$ \\
$<0.08$ & $<2.0$ & 0.21 & $<0.013$ & $<0.8$ & 0.03 & $<0.0036$ \\
\hline Reheating temperature & $1100-1180^{\circ} \mathrm{C}$ & & \\
Cooling start-temperature & Above $A r_{3}$ & & \\
Finish rolling temperature & Above $A r_{3}$ & & \\
Coiling temperature & $>500^{\circ} \mathrm{C}$ & & \\
\hline
\end{tabular}

Table 2: Tensile test data. 'L', 'D' and ' $T$ ' stand for longitudinal, diagonal and transverse orientations of the test specimen.

\begin{tabular}{ccccc}
\hline Orientation & $\begin{array}{c}\text { Yield strength } \\
\mathrm{MPa}\end{array}$ & $\begin{array}{c}\text { Ultimate strength } \\
\mathrm{MPa}\end{array}$ & $\begin{array}{c}\text { Total elongation } \\
\%\end{array}$ & $\begin{array}{c}\text { Uniform elongation } \\
\%\end{array}$ \\
\hline $\mathrm{L}$ & $601 \pm 35$ & $676 \pm 4$ & $13 \pm 2$ & $7 \pm 2$ \\
$\mathrm{D}$ & $600 \pm 35$ & $663 \pm 10$ & $16 \pm 2$ & $8 \pm 2$ \\
$\mathrm{~T}$ & $634 \pm 29$ & $707 \pm 16$ & $15 \pm 1$ & $7 \pm 1$ \\
\hline
\end{tabular}




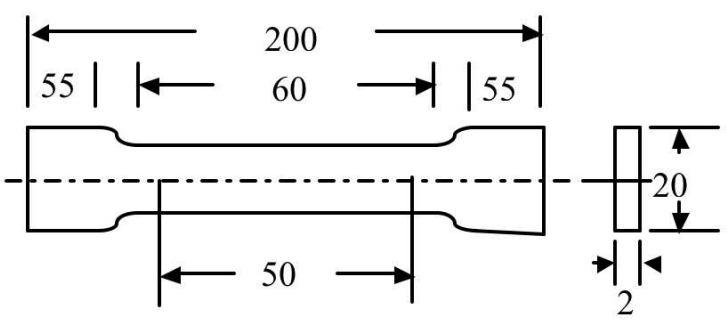

(a)

(b)
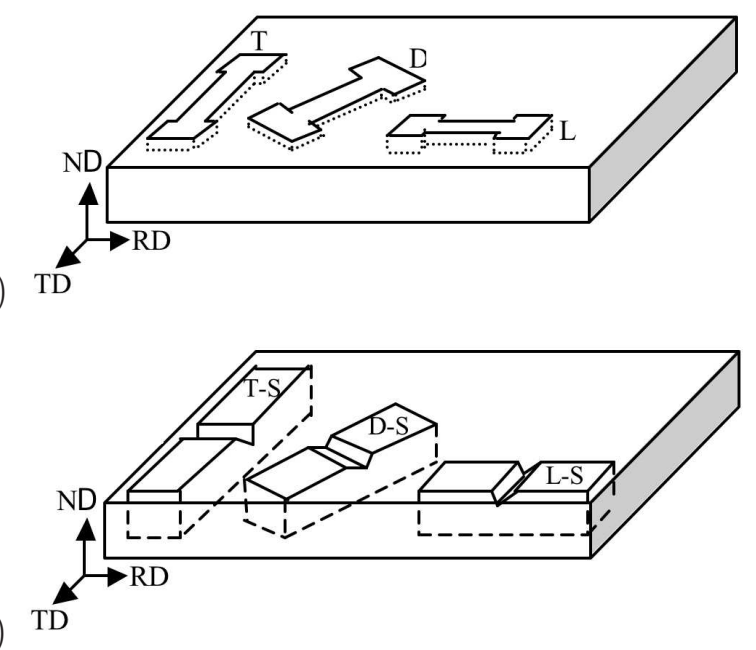

(c)

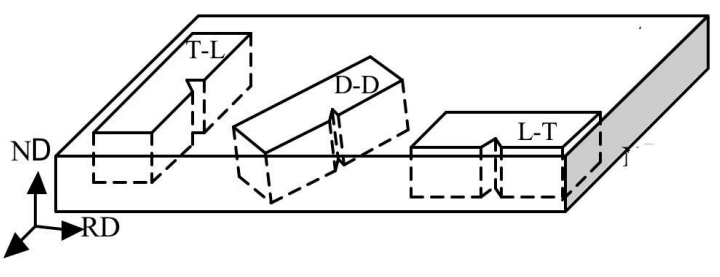

(d)

Figure 1: Orientations of mechanical test samples relative to steel plate, where 'RD', 'TD' and 'ND' stand for the rolling, transverse and normal directions. (a) Dimensions of tensile sample in mm. (b) Orientations of tensile test samples. (c) Conventional orientations of Charpy specimens. (d) Additional orientations of Charpy specimens. 
(a)

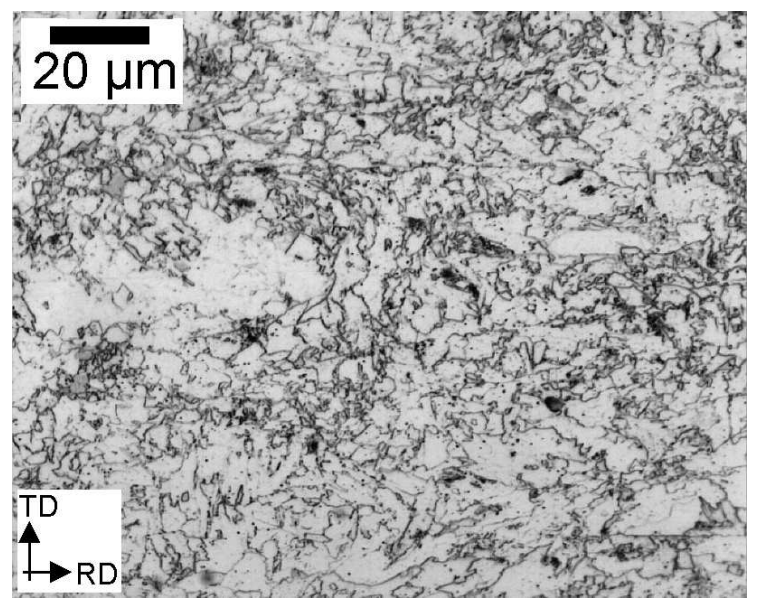

(c)

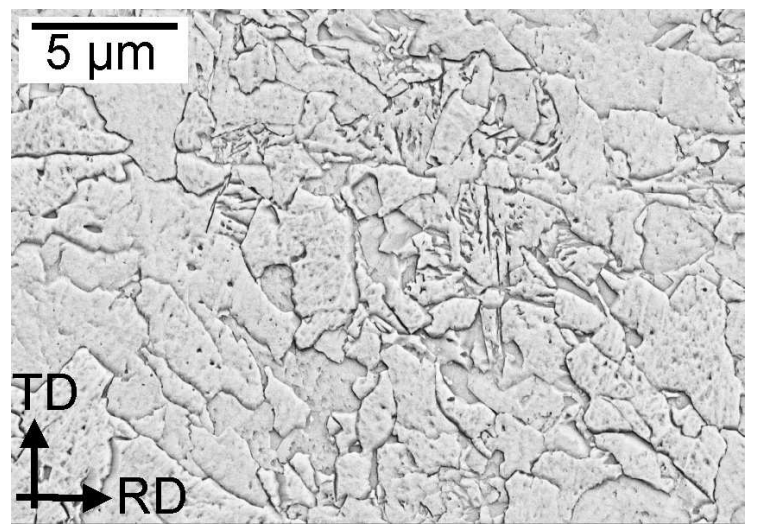

(b)

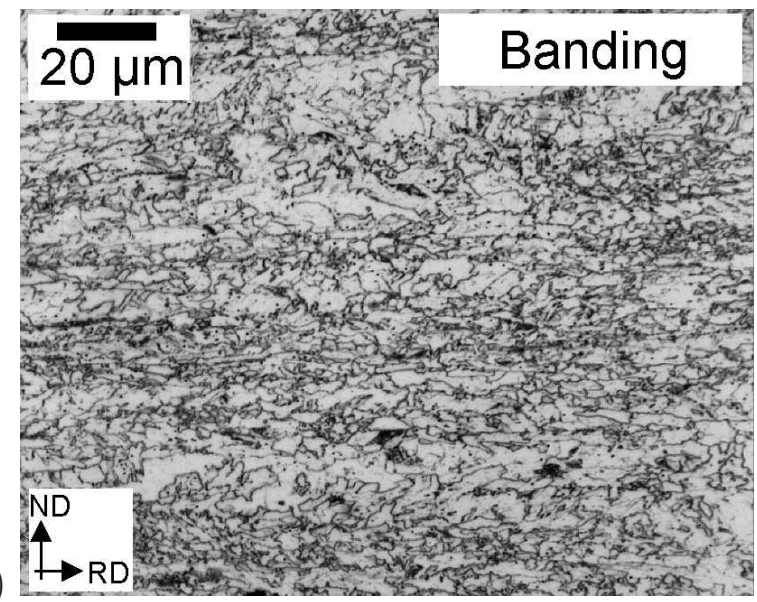

(d)

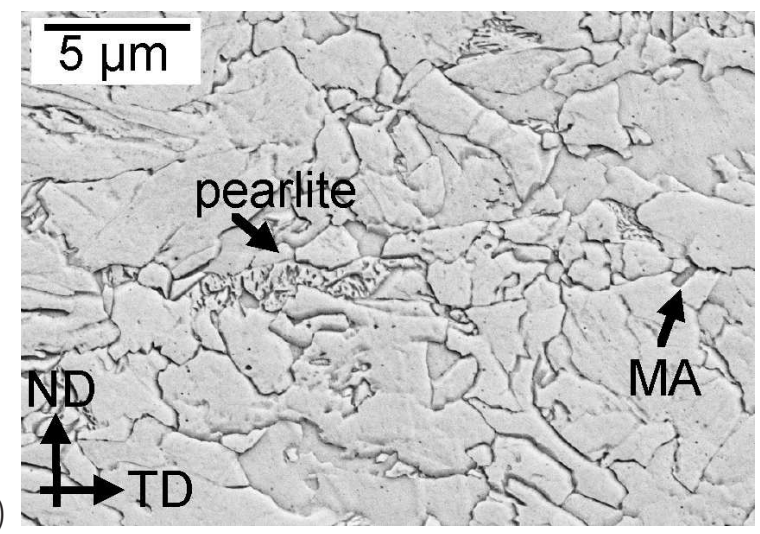

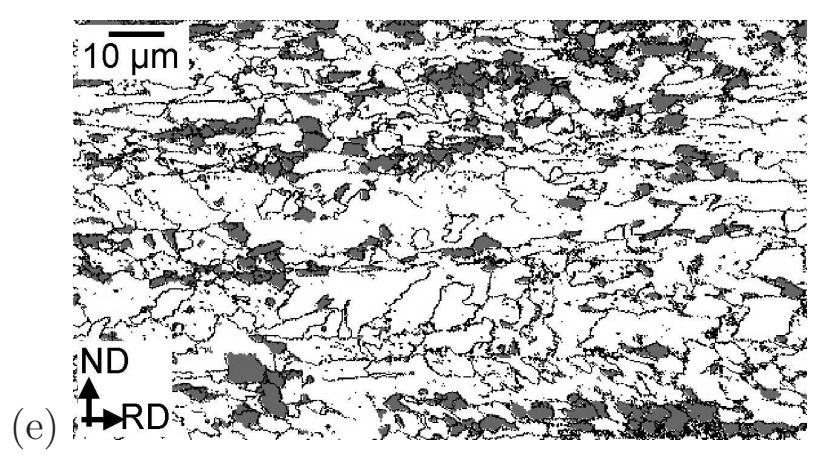

Figure 2: (a,b) Optical micrographs, (c,d) scanning electron micrographs, (e) grain orientation map with values misorientations greater than $15^{\circ}$ identified as boundaries. 

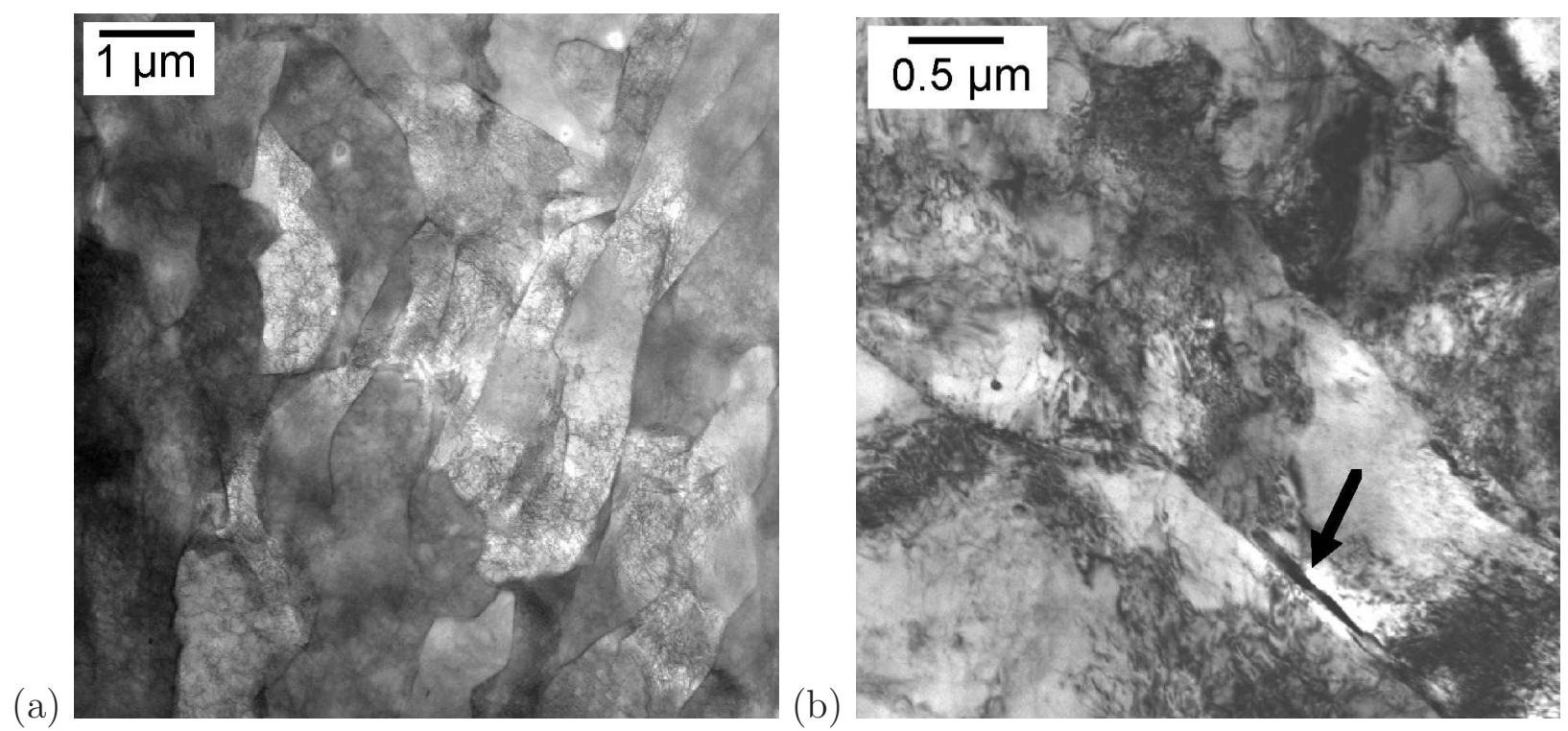

Figure 3: Transmission electron micrographs of (a) coarse-grained region (STEM image) and (b) 'acicular' ferrite region with cementite (TEM image).
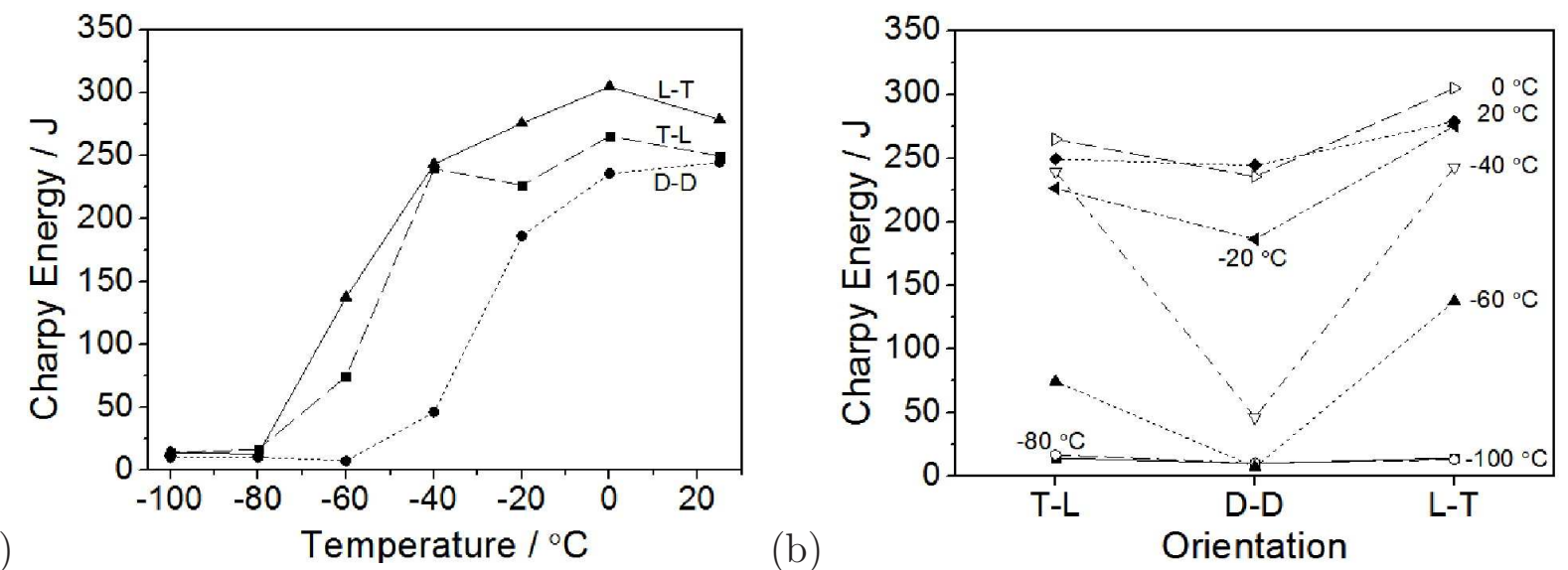

(a)

(b)

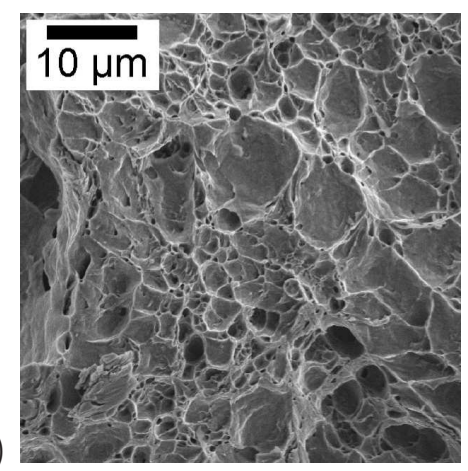

(d)

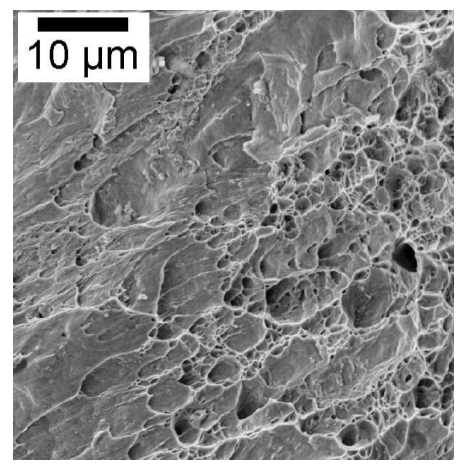

(e)

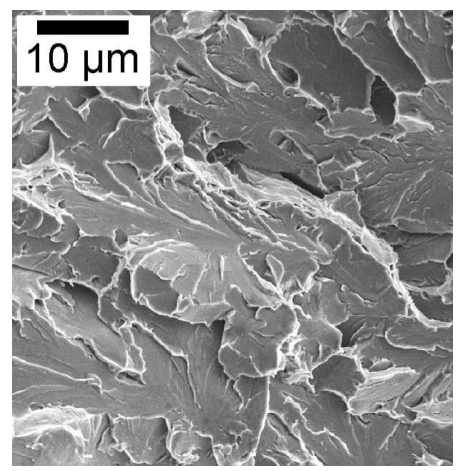

Figure 4: Charpy impact test results for 'conventional' notch orientations. (a) As a function of temperature, (b) as a function of orientation. (c-e) Fracture surfaces of $\mathrm{L}-\mathrm{T}$ orientation Charpy specimens broken at room temperature, $-60^{\circ} \mathrm{C}$, and $-100^{\circ} \mathrm{C}$ respectively. 


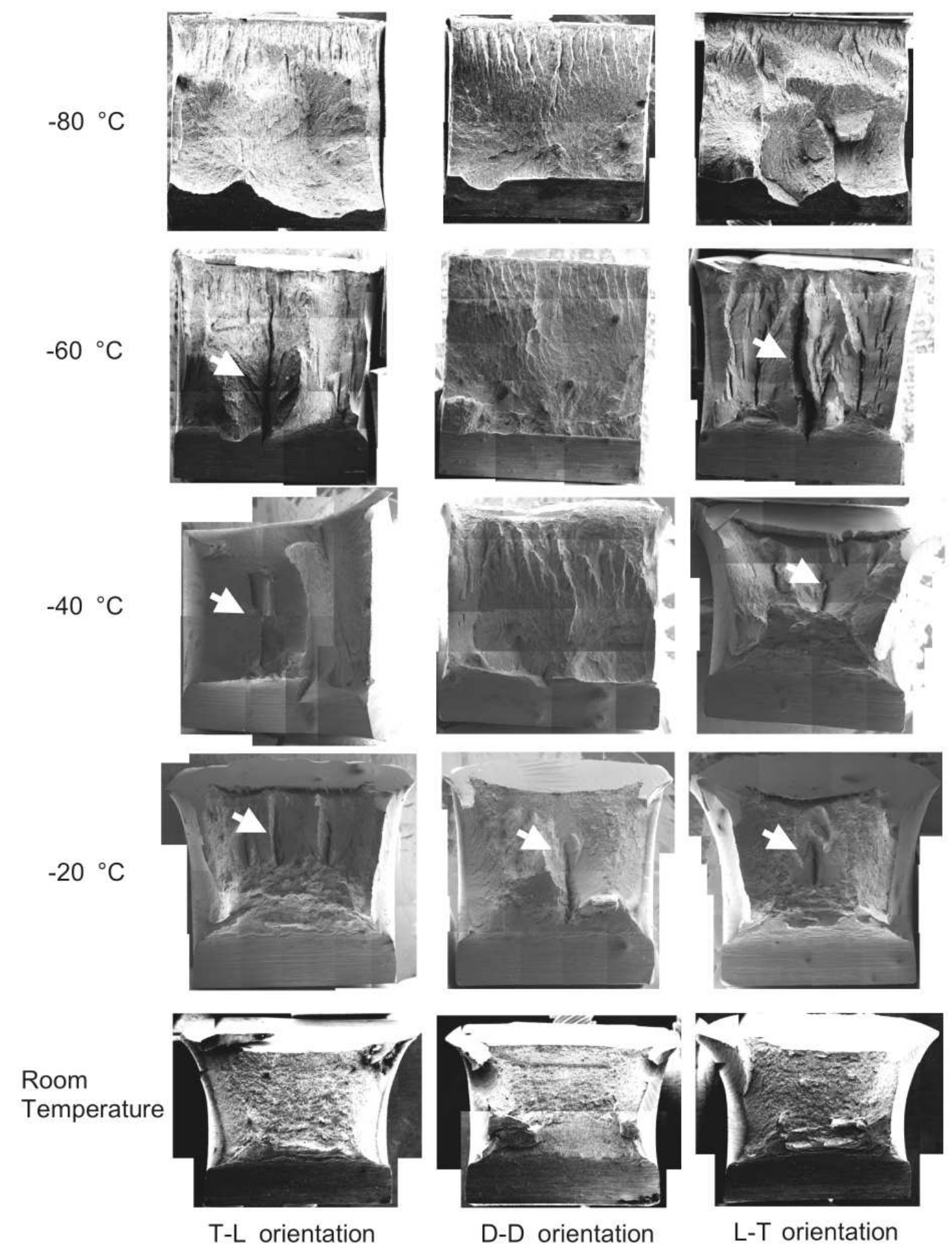

Figure 5: Fracture surfaces of Charpy specimens with delamination indicated by white arrows. 


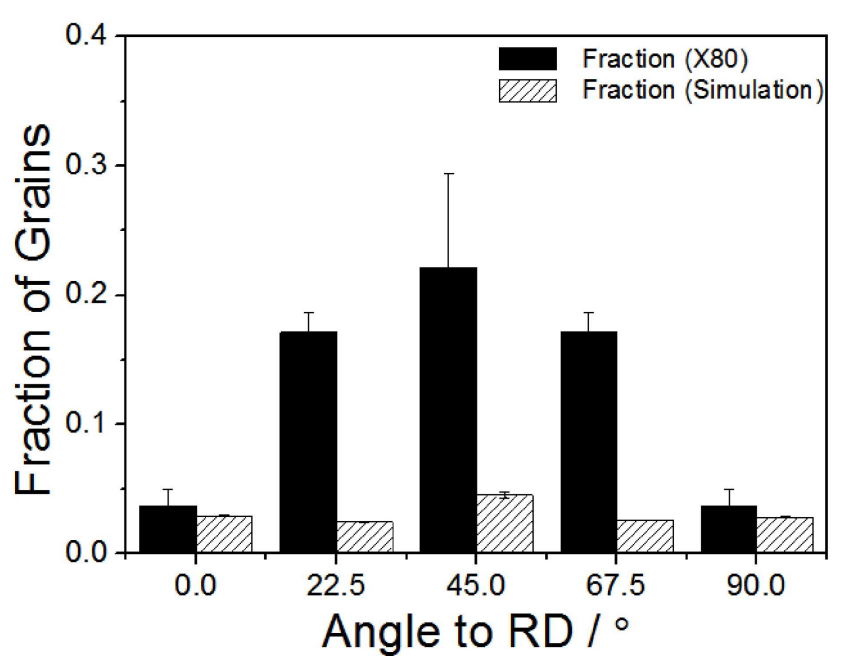

(a)

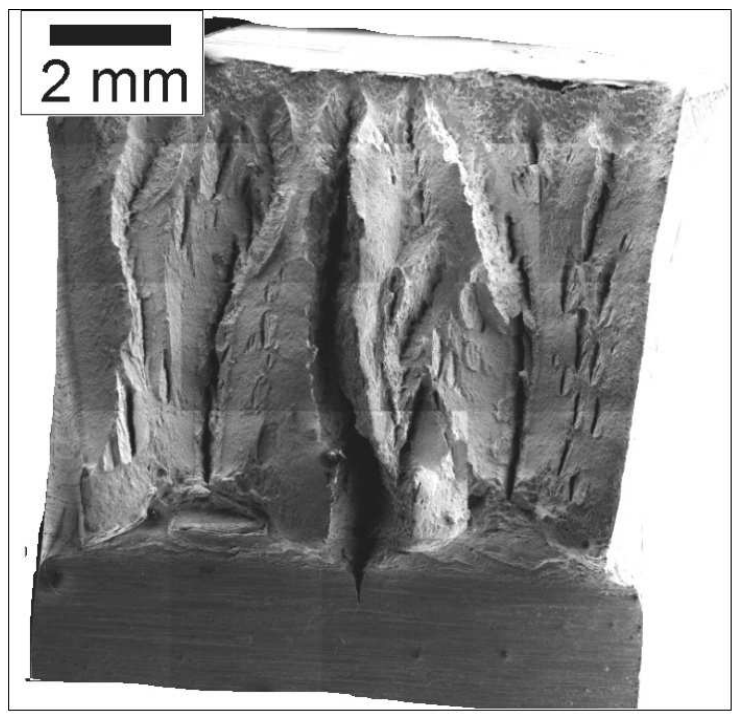

(b)

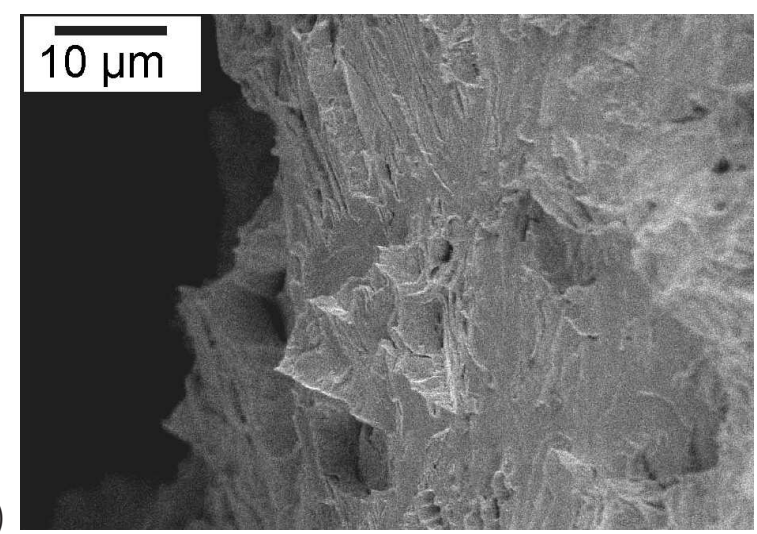

Figure 6: Fraction of grains which within the tolerance angle of $11.25^{\circ}$ have a $\{100\}$ plane parallel to the fracture surface, as a function of angle between the normal to the $\{100\}$ planes and the rolling direction. Notice that the sum of all the fractions from $\mathrm{X} 80$ or the simulation does not equal 1 because not all grains will have their $\{100\}$ parallel to the fracture surface within the tolerance angle.

Figure 7: Fracture surfaces of an $\mathrm{L}-\mathrm{T}$ orientation Charpy specimen broken at $-60^{\circ} \mathrm{C}$. (a) Overall features. (b) Showing cleavage within the large delamination illustrated in (a). 
(a)

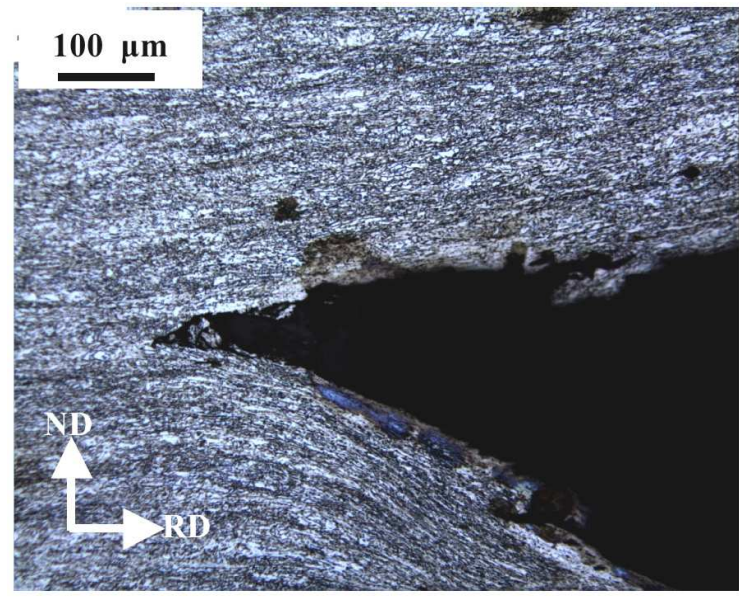

(b)
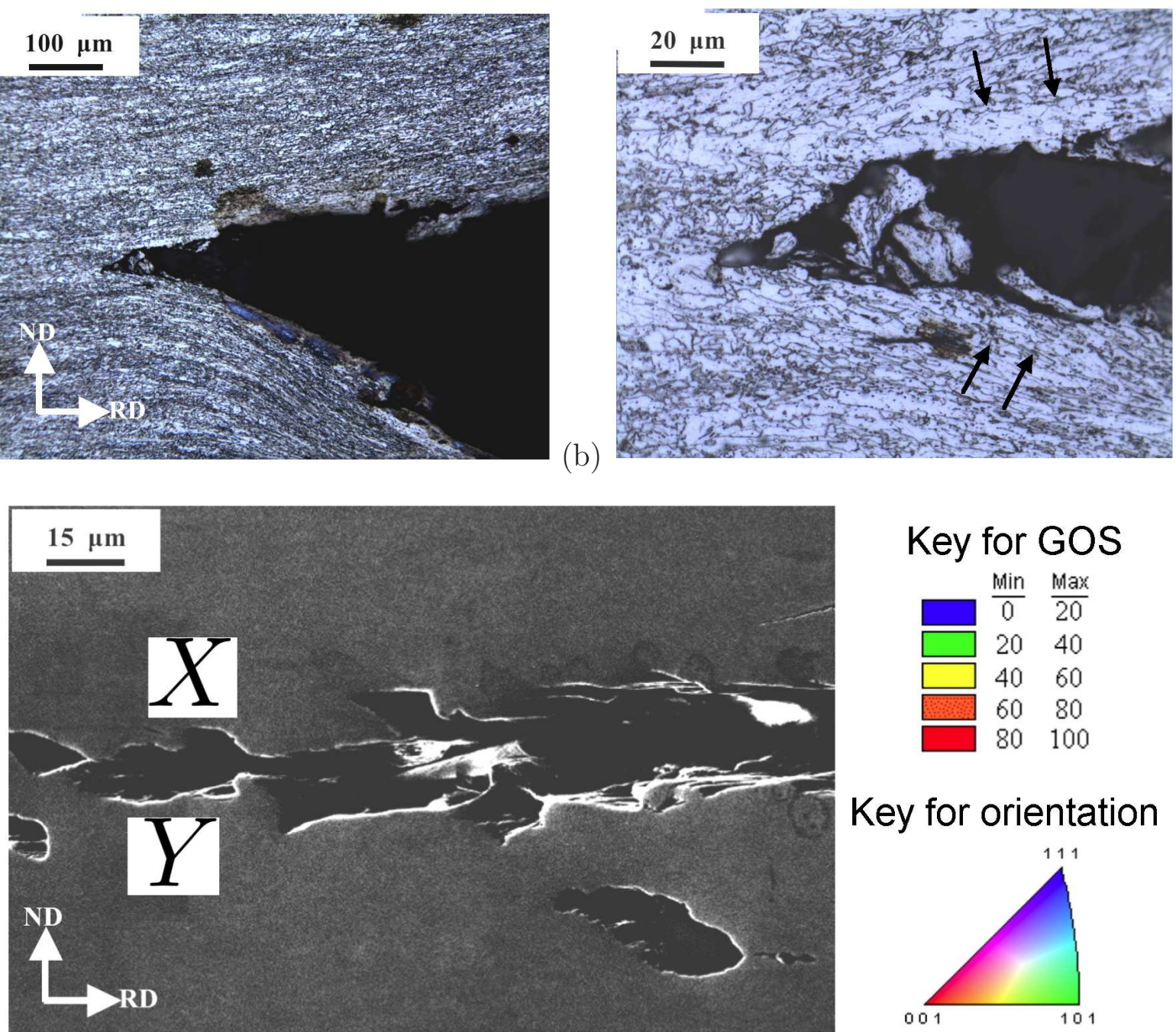

Key for GOS

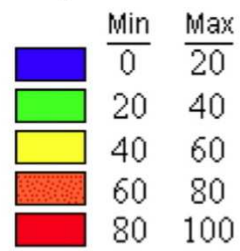

Key for orientation
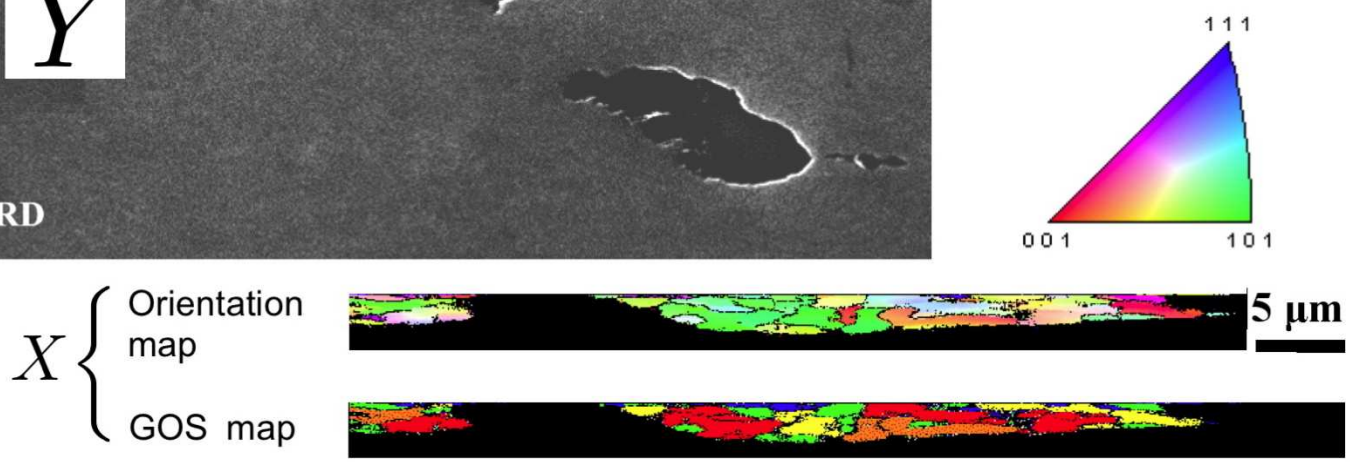

$Y\left\{\begin{array}{l}\text { GoS map } \\ \text { Orientation } \\ \text { map }\end{array}\right.$

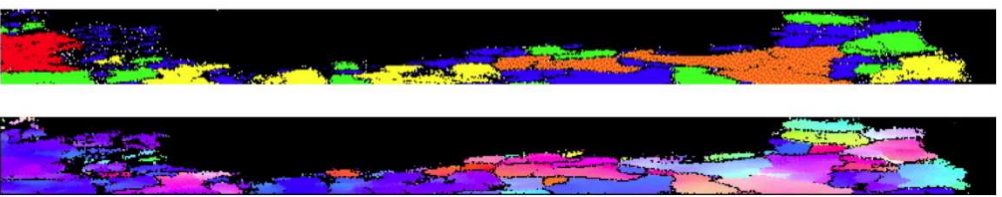

(c)

Figure 8: Delamination, L-T orientation Charpy sample broken at $-40^{\circ} \mathrm{C}$. (a,b) Optical micrographs showing the relationship to microstructural banding, (b) corresponding SEM image, orientation maps and grain orientation spread (GOS) maps with the key in degrees. 


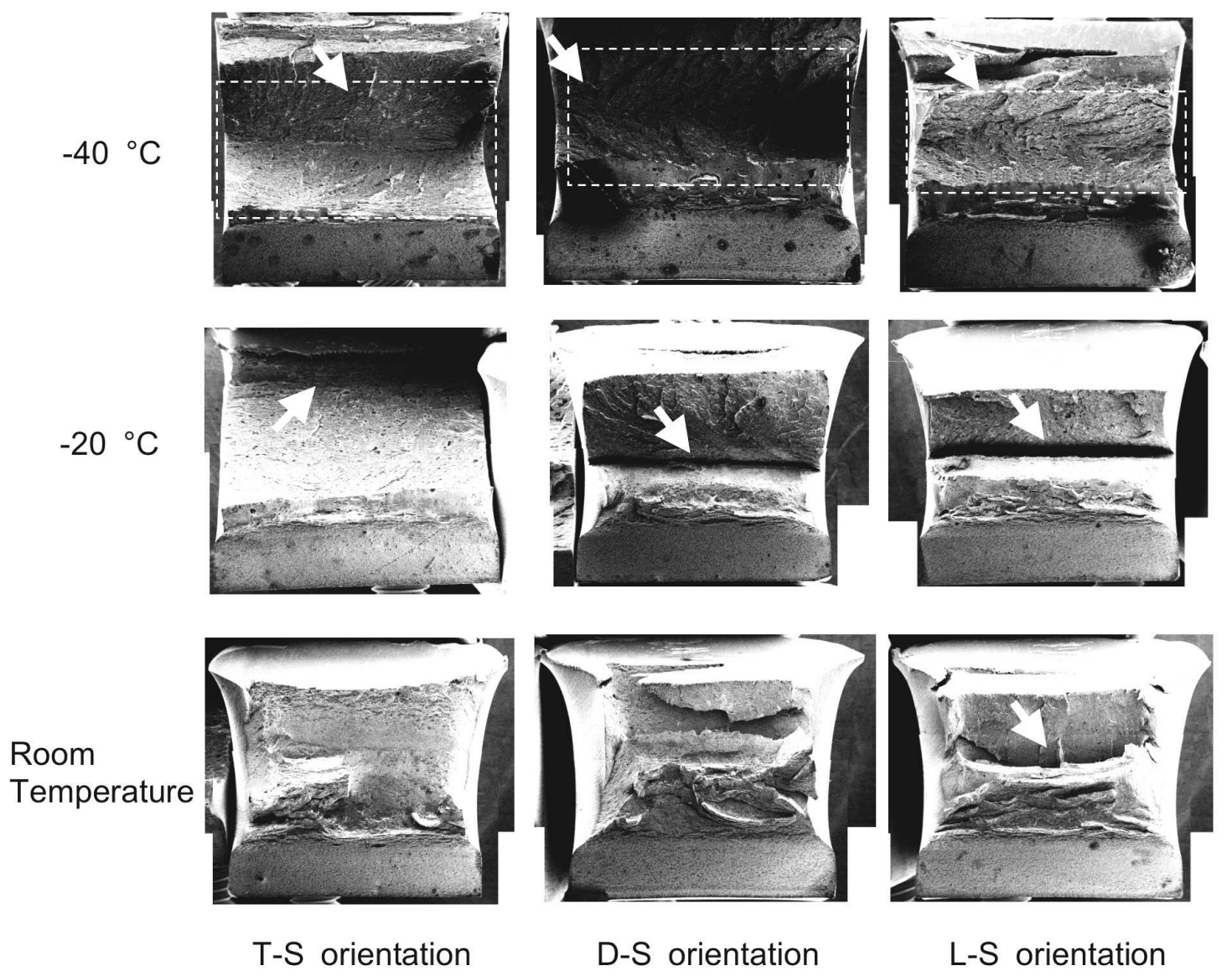

Figure 9: Fracture surfaces of additional Charpy specimens with notch parallel to the rolling plane, with delamination indicated by white arrows.
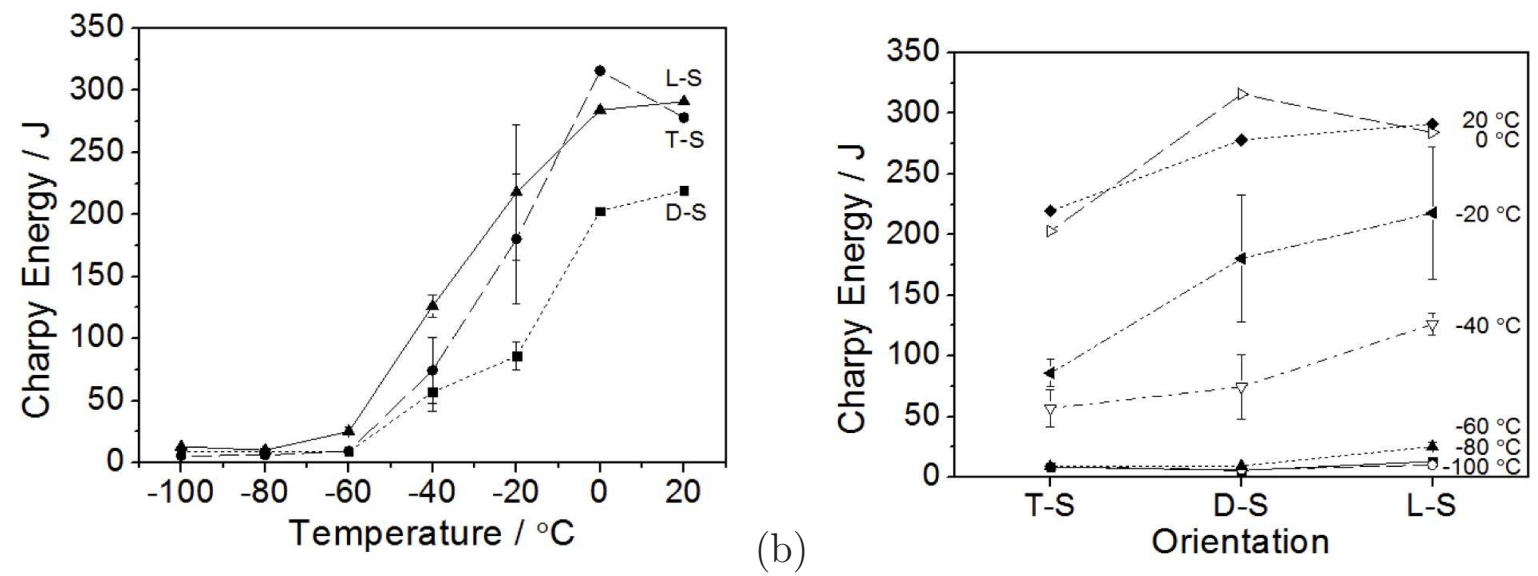

Figure 10: Charpy impact test results for samples in which the notch is parallel to the rolling plane. (a) As a function of temperature, (b) as a function of orientation. 